\title{
An observational study of the direct costs related to hospital admissions, mortality and premature death associated with liver disease in Portugal
}

\author{
Sofia Vitor ${ }^{1 *}$, Rui Tato Marinho ${ }^{1}$, José Gíria² and José Velosa ${ }^{1}$
}

\begin{abstract}
Background: Liver disease, one of the most common causes of hospitalization worldwide, is particularly prevalent in Europe. This study aimed to determine the number of hospital discharges and admissions, mortality, premature death and costs associated with liver disease from the perspective of the National Health Service in Portugal.

Methods: A descriptive, retrospective analysis of data from 97 hospitals between 2000 and 2008, and mortality data for 2011 collected from the Portuguese National Institute of Statistics. The 9th and 10th revisions of the international classification of diseases were used to establish diagnoses. National data on demographics, average length of stay, in-patient mortality and direct costs associated with hospital admissions and liver transplantation were compared for the most common liver diseases. Mortality and premature death were compared using the potential years of life lost (PYLL) index.

Results: The annual mean number of discharges for liver disease was 11,503 between 2000 and 2008. Most cases of liver disease were diagnosed in men (70.4\%) and the prevalence of liver disease peaked in patients aged from 20 to 64 years (60.7\%). Alcoholic cirrhosis was the most frequent liver-disease diagnosis leading to discharge (38.6\%). In addition, alcoholic cirrhosis emerged as the main cost-driver, accounting for $€ 26,818,930$ (42.6\%) of the total cost imposed by liver disease. Overall, chronic hepatic disease was the 10 th most common cause of mortality in Portugal in 2011, causing 21.8 deaths per 100,000. Chronic hepatic disease and hepatocellular carcinoma are even more important causes of premature death, ranking third based on PYLL.

Conclusion: In 2011, liver disease was the 10th most common cause of death and the third most important cause of premature death in Portugal. Alcohol cirrhosis was the leading cause of liver-related hospital admissions between 2001 and 2008. It appears that liver disease imposes a considerable social and economic burden on Portugal. Our results suggest that educational, legislative and therapeutic interventions to prevent morbidity, mortality and premature death from liver disease are urgently required to minimise the economic and clinical burdens.
\end{abstract}

Keywords: Portugal, Liver disease, Premature death, Direct costs, Mortality

JEL Classification: 1110, 1140, I180, H510

\footnotetext{
*Correspondence: sivvitor@gmail.com

${ }^{1}$ Department of Gastrenterology and Hepatology, Hospital de Santa

Maria, Centro Hospitalar Lisboa Norte, Avenida Professor Egas Moniz,

1649-035 Lisbon, Portugal

Full list of author information is available at the end of the article
} 


\section{Background}

Liver disease, one of the most common causes of hospitalization worldwide, $[1,2]$ is particularly prevalent in Europe [3]. Indeed, liver disease was the seventh most common cause of death in Europe during 2010 [4]. Chronic hepatitis, cirrhosis and hepatocellular carcinoma (HCC) are the most common liver diseases in Europe $[3,5]$. Viruses and alcohol account for more than $75 \%$ of cases of liver disease in Portugal [6]. For example, cirrhosis frequently causes morbidity and mortality [79], and the direct and indirect financial costs associated with liver diseases impose a considerable socioeconomic burden on health services and society [10].

Against this background, economic evaluations from the perspective of the Portuguese National Health Service inform policies to promote prevention and management of liver disease and other health problems $[1,2$, 11-14]. However, although health professionals recognize liver diseases as a common cause of morbidity and mortality in Portugal [7, 9], few studies estimate the socioeconomic impact. Therefore, our study aims to determine the profile of patients admitted with liver disease between 2001 and 2008, including details of the average length of stay (ALOS), mortality among inpatients, and direct costs specifically associated with hospital admissions due to liver diseases to the National Health Service of Portugal. In addition, to place these results in context, we compared mortality and potential years of life lost (PYLL) associated with liver disease to those associated with other common conditions. This included all national deaths to common conditions, occurring both inside and outside of hospital, in 2011.

\section{Methods}

Population

This descriptive, retrospective analysis uses freely available admission and discharge data already in the public domain, which was obtained from the Portuguese Directorate General for Health or the 'Direcção Geral de Saude' (DGS). This included data from 97 public hospitals in the Portuguese National Health Service categorized using diagnosis related-groups (AP21 version) between 2000 and 2008. This timeframe was decided based on the available data as the time of data analysis. Patient variables (sex, age, mortality and ALOS) were analyzed using Excel 2003. All patients admitted by liver disease from 2000 to 2008 were included and their variables (sex, age, mortality and ALOS) were analyzed using Excel 2003. To identify the group of inpatients that included liver diseases, ICD-codes were used as a filter.

In addition, demographic data and mortality from 2011 were collected from another source, the Portuguese National Institute of Statistics [Instituto Nacional de
Estatística (INE)] website (http://www.ine.pt) and analyzed using Excel 2003. This allowed us to quantify the mortality associated with liver disease and compare it with the mortality associated with other common causes of death in Portugal.

\section{Diagnoses of admissions and discharges}

Data was obtained from the DGS for the most frequent causes of liver diseases (2000-2008) (Table 1), which were established using the international classification of diseases (ICD) 9th revision, clinical modification, (ICD-9CM). Using ICD-10 (2008 version), we determined the disease categories that caused more deaths than liver disease in 2011 (Table 2).

\section{Direct costs}

We calculated the direct costs paid by Portuguese National Health Service for in-patients admitted to all 97 public hospitals with liver diseases between January 2000

Table 1 Categories of liver diseases

\begin{tabular}{|c|c|}
\hline Disease category & ICD 9 CM Code \\
\hline Viral hepatitis & 070 \\
\hline HBV & $070.3-070.4$ \\
\hline $\mathrm{HCV}$ & $070.41,070.44,070.51,070.54,070.7$ \\
\hline Cirrhosis & 571 \\
\hline Alcoholic cirrhosis & 571.2 \\
\hline Non-alcoholic cirrhosis & 571.5 \\
\hline $\mathrm{HCC}$ & 155.0 \\
\hline Other $^{\mathrm{a}}$ & 570-573, excluding codes above \\
\hline
\end{tabular}

Table 2 Categories of diseases with greater mortality than liver diseases in 2011

\begin{tabular}{|c|c|c|}
\hline Disease category & Disease subcategory & ICD-10 Code \\
\hline \multicolumn{2}{|c|}{ Cerebrovascular disease } & $160-169$ \\
\hline \multicolumn{2}{|c|}{ Chronic hepatic disease and cirrhosis } & K70-K77, B15-B19 \\
\hline \multicolumn{2}{|l|}{ Diabetes } & E10-E14 \\
\hline \multicolumn{2}{|l|}{$\mathrm{HCC}$} & C22.0 \\
\hline \multicolumn{2}{|l|}{ HIV } & B20-B24 \\
\hline \multicolumn{2}{|c|}{ Ischemic heart disease } & $120-125$ \\
\hline \multicolumn{2}{|l|}{ Malignant neoplasm } & C18-C20 \\
\hline & Female breast & $\mathrm{C} 50$ \\
\hline & Prostate & C61 \\
\hline & Stomach & $\mathrm{C} 16$ \\
\hline & Bronchus and lung & C33-C34 \\
\hline \multicolumn{2}{|c|}{ Motor vehicle traffic accidents } & V01-V89 \\
\hline \multicolumn{2}{|l|}{ Pneumonia } & J09-J18 \\
\hline
\end{tabular}


and December 2008. Private institutions do not provide data to the DGS, nor is this data in the public domain. We also collected ALOS and the amount paid per day and for each admission, including medication, examinations, medical and nursing support, from hospital databases (all included in information obtained from the DGS). Therefore, this analysis includes the costs associated with inpatient stay only (e.g., drug costs, nursing, consultation and invasive treatment). Ambulatory costs were not available and any outpatient costs have not been captured. The total costs of inpatient care were produced as a function of ALOS and the amount paid per day per patient. No adjustment for cost was made depending on the reference year.

The authors of this study feel it is important to capture the costs related to liver transplantation as it is the only treatment that solves end-stage liver disease. Costs related to liver transplantation were collected and analyzed separately to the inpatient costs of liver disease outlined above. Some other treatments, such as albumin dialysis, are used as a bridge to liver transplantation and are often performed during the same admission.

\section{Premature death}

Lost earnings due to morbidity and premature mortality is one of the most important drivers of indirect costs [15]. Therefore, we collected mortality data for people aged 70 years of age and younger, including stratification by cause and sex, from INE registries for 2011. Diseases considered were classified using ICD-10 codes. Based on this, we estimated the PYLL, a summary measure of premature mortality which provides an explicit way of weighting deaths occurring at younger ages, which are, a priori, preventable. The calculation of PYLL involves summarising deaths occurring at each age and multiplying this with the number of remaining years to live up to a selected age limit. In order to assure cross-country comparisons when calculating PYLL, a limit of 70 years is used [16]. This is an established method to describe specific patterns in premature mortality and a mechanism for establishing healthcare priorities [17]. In this study, PYLL values were calculated for people aged 70 years old and under, and those occurring due to liver disease were compared to those due to other conditions.

\section{Results}

\section{Sample}

The mean number of hospital discharges for liver disease was 11,503 annually. The number of discharges attributable to liver disease decreased slightly between 2000 $(11,617)$ and $2008(10,503)$ (Table 3). Cirrhosis remained the main cause of admission for liver disease between 2000 and 2008. Over the same time, discharges due to
Table 3 Number of discharges diagnosed with liver disease between 2000 and 2008

\begin{tabular}{llllll}
\hline Year & \multicolumn{5}{l}{ Number diagnosed with liver disease } \\
\cline { 2 - 6 } & Viral hepatitis & Cirrhosis & HCC & Other $^{\mathbf{a}}$ & All \\
\hline 2000 & 1509 & 5313 & 684 & 4111 & 11,617 \\
2001 & 1317 & 5821 & 689 & 3755 & 11,582 \\
2002 & 1744 & 5995 & 743 & 4067 & 12,549 \\
2003 & 1599 & 5770 & 774 & 4330 & 12,473 \\
2004 & 1399 & 5637 & 862 & 3963 & 11,861 \\
2005 & 1087 & 5530 & 834 & 3997 & 11,448 \\
2006 & 811 & 5431 & 862 & 3766 & 10,869 \\
2007 & 811 & 5151 & 912 & 3752 & 10,627 \\
2008 & 674 & 4769 & 1127 & 3933 & 10,503 \\
\hline
\end{tabular}

a Includes: hepatoptosis; alcoholic liver damage unspecified; autoimmune hepatitis; toxic hepatitis; hepatitis unspecified

viral hepatitis almost halved (1509 and 674) while discharges for HCC doubled (684 and 1127).

Table 4 summarizes the number of discharges stratified by liver disease. Cirrhosis, mainly caused by alcohol abuse, was the most frequent indication leading to discharge (38.6\%), corresponding to 58.2 cases per 100,000 inhabitants. HCC was the second most common cause of hospital discharge, corresponding to 40 cases per 100,000 inhabitants. In general, males are more likely to be discharged with a liver disease than women (70.4 versus $29.6 \%$; overall discharge ratio: $2.4: 1$ ), with the greatest sex differences in HCC (3.8:1) and alcoholic cirrhosis (3.5:1). In 2008, the proportion of discharged patients aged from 20 to 64 years old was highest for hepatitis $C$ virus $(\mathrm{HCV})(86.9 \%)$, followed by viral hepatitis generally

Table 4 Number of discharges by liver disease categories and sex in 2008

\begin{tabular}{lllll}
\hline $\begin{array}{l}\text { Disease } \\
\text { category }\end{array}$ & $\begin{array}{l}\text { Disease } \\
\text { subcat- } \\
\text { egory }\end{array}$ & $\begin{array}{l}\text { Number } \\
\text { of } \\
\text { discharges }\end{array}$ & $\begin{array}{l}\text { \% of all } \\
\text { discharges }\end{array}$ & $\begin{array}{l}\text { Discharge } \\
\text { ratio } \\
\text { male:female }\end{array}$ \\
\hline $\begin{array}{l}\text { Viral hepa- } \\
\text { titis }\end{array}$ & All & 674 & 6.4 & 2.0 \\
Cirrhosis & All & 210 & 2.0 & 2.1 \\
& Alcoholic & 4053 & 38.6 & 2.4 \\
& Cirrhosis & 386 & 3.7 & 3.0 \\
& Non- & 716 & 6.8 & 1.4 \\
HCC & alcoholic & & 45.4 & \\
Other & cirrhosis & & 10.7 & 3.8 \\
All & & 1127 & 37.4 & 1.7 \\
\hline
\end{tabular}

a Includes: hepatoptosis; alcoholic liver damage unspecified; autoimmune hepatitis; toxic hepatitis; hepatitis unspecified 
(Fig. 1). Overall, this age group accounted for $60.7 \%$ of patients discharged with liver disease in 2008.

\section{ALOS and mortality}

The ALOS for liver disease discharges overall and stratified by condition in 2008 was approximately 10 days, which showed little variation from 2000 to 2008. However, Fig. 2 shows that the ALOS for alcoholic cirrhosis decreased from 13 to 8 days during this time. In 2008, HCC and non-alcoholic cirrhosis were associated with the highest ALOS. Viral hepatitis had the shortest ALOS.

Table 5 shows mortality rates between 2000 and 2008 . In 2008, HCC emerged as having the highest mortality rate among liver diseases $(22.6 \%)$, followed by alcoholic $(14.9 \%)$ and non-alcoholic cirrhosis (13.4\%). Mortality rate for all liver disease discharges increased from $10.4 \%$ in 2000 to $13.1 \%$ in 2008 .

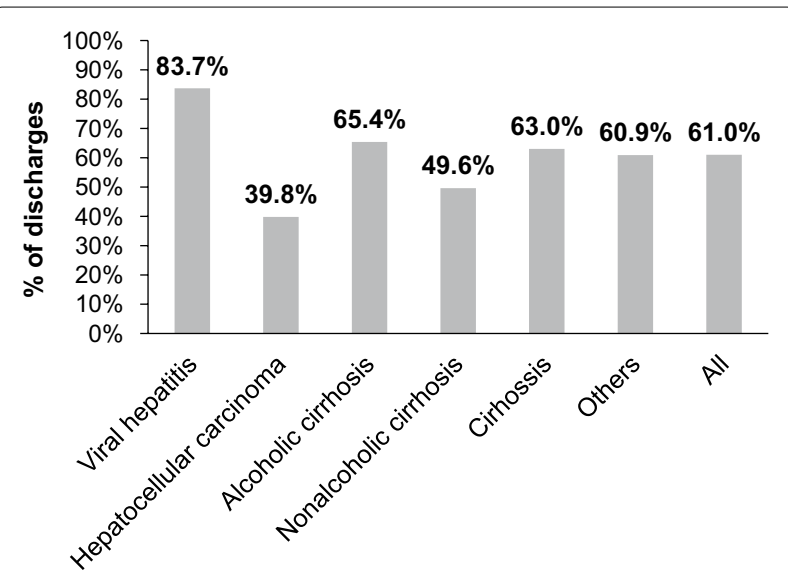

Fig. 1 Proportion (\%) of discharges among people aged 20-64 years in $2008(n=10,503)$

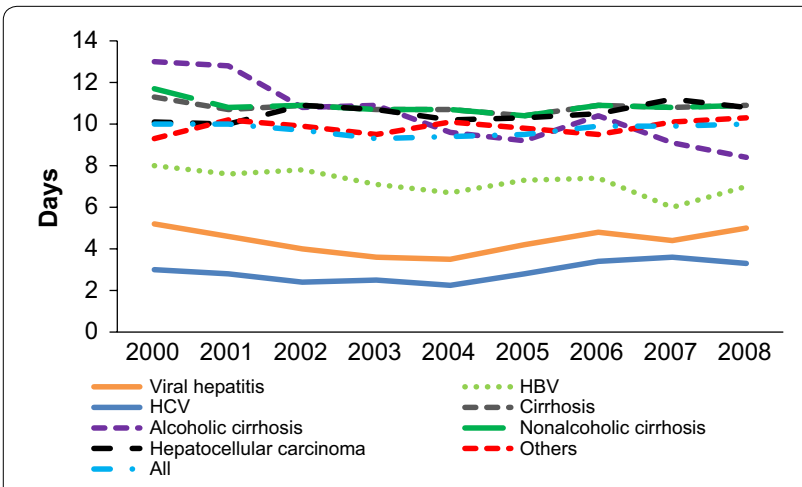

Fig. 2 Average length of stay for liver diseases discharges (20002008) (HBV hepatitis B, HCV hepatitis C virus)

\section{Direct costs of hospital admission}

Figure 3 shows the direct hospital costs for in-patients for eight disease categories. In 2008, liver disease was associated with the third highest amount payed by the Public Health Service in terms of hospital admissions $(€ 62,950,631)$, exceeded by ischemic heart disease $(€ 167,538,693)$ and cerebrovascular disease $(€ 80,387,569)$.

Alcoholic cirrhosis emerged as the main cost-driver (Table 6), accounting for $€ 26,818,930,42.6 \%$ of the total cost imposed by liver disease. This proportion far exceeded the cost imposed by HCC, which was $€ 9,737,184$ (15.5\%), the second most resource-intensive condition. Table 7 shows the direct costs incurred by hospitals based on an analysis of 148 liver transplants performed during 2008 excluding those associated with follow-up visits and transplant-related therapy such as immunosuppressive drugs. Again, alcoholic cirrhosis and HCC emerged as the main cost-drivers, accounting for $€ 5,876,883$ (38.5\%) and $€ 4,330,335$ (28.5 \%) of overall costs associated with liver transplants respectively.

\section{Mortality and premature death}

Overall, chronic hepatic disease (which includes cirrhosis and HCC) was the 10th most common cause of mortality in Portugal in 2011, causing 21.8 deaths per 100,000 inhabitants (Table 8). However, chronic hepatic disease and HCC are even more important causes of premature death (Table 9), ranking third based on PYLL.

\section{Discussion}

Liver disease is one of the most common chronic diseases in Portugal. Hospital admissions from hepatic disease peak in males aged between 20 and 60 years. This group is the most socioeconomically active group in terms of contribution to the general economy and to individual families in Portuguese society $[18,19]$. The high rate of liver disease in this group is likely to impose a considerable indirect burden on the economy (e.g., through lost productivity, benefit payments and lost taxation) and families.

The pattern of mortality underscores the economic burden imposed by liver disease. Overall, in 2011 liver disease was the tenth most common cause of death in Portugal. However, hepatic disorders were the third most common cause of premature death (i.e., in people less than 70 years of age). Therefore, interventions aimed at reducing the number of cases of liver disease in this group could reduce the socioeconomic burden and mortality imposed by liver disease [20].

This analysis focused on the direct medical costs paid by public health insurance due to hospitalization, medication and human resources, estimated to be $€ 62,950,631$ 
Table 5 Mortality rate for liver diseases discharges (2000-2008)

\begin{tabular}{|c|c|c|c|c|c|c|c|c|c|}
\hline \multirow[t]{2}{*}{ Year } & \multicolumn{9}{|c|}{ Mortality rate by disease category (\%) } \\
\hline & Viral hepatitis & HBV & $\mathrm{HCV}$ & Cirrhosis & $\begin{array}{l}\text { Alcoholic } \\
\text { cirrhosis }\end{array}$ & $\begin{array}{l}\text { Nonalcoholic } \\
\text { cirrhosis }\end{array}$ & HCC & Other ${ }^{a}$ & All \\
\hline 2000 & 0.9 & 0.9 & 0.4 & 13.1 & 13.4 & 11.6 & 26.5 & 7.8 & 10.4 \\
\hline 2001 & 1.5 & 2.3 & 0.6 & 14.5 & 14.4 & 14.7 & 26.1 & 9.4 & 12.0 \\
\hline 2002 & 1.2 & 2.0 & 1.0 & 14.2 & 14.7 & 11.9 & 24.5 & 8.7 & 11.2 \\
\hline 2003 & 1.5 & 3.3 & 0.8 & 13.6 & 13.4 & 15.2 & 28.3 & 9.3 & 11.5 \\
\hline 2004 & 1.2 & 2.8 & 0.6 & 13.4 & 13.4 & 13.2 & 25.1 & 10.6 & 11.9 \\
\hline 2005 & 1.7 & 2.3 & 1.5 & 13.7 & 13.7 & 13.7 & 26.7 & 9.5 & 12.0 \\
\hline 2006 & 1.4 & 1.5 & 1.2 & 14.3 & 14.4 & 13.7 & 25.4 & 10.4 & 12.9 \\
\hline 2007 & 2.2 & 2.1 & 2.5 & 15.3 & 15.1 & 16.2 & 24.1 & 10.8 & 13.5 \\
\hline 2008 & 2.8 & 4.8 & 2.1 & 14.6 & 14.9 & 13.4 & 22.6 & 10.4 & 13.1 \\
\hline
\end{tabular}

a Includes: hepatoptosis; alcoholic liver damage unspecified; autoimmune hepatitis; toxic hepatitis; hepatitis unspecified

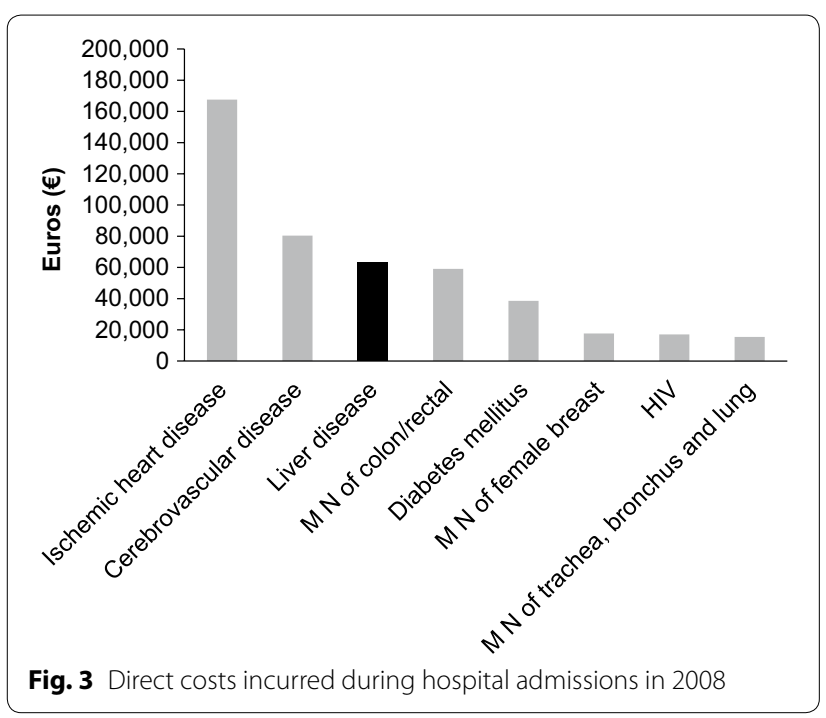

Table 6 Direct costs incurred during hospital admissions for liver diseases in $\mathbf{2 0 0 8}$

\begin{tabular}{llrl}
\hline $\begin{array}{l}\text { Disease } \\
\text { category }\end{array}$ & $\begin{array}{l}\text { Disease subcat- } \\
\text { egory }\end{array}$ & Direct costs $(\boldsymbol{\epsilon})$ & \% of direct costs \\
\hline Viral hepatitis & All & $2,647,742$ & 4.2 \\
& HBV & 820,639 & 1.3 \\
& HCV & $1,515,620$ & 2.4 \\
Cirrhosis & All & $32,138,385$ & 51.1 \\
& Alcoholic cir- & $26,818,930$ & 42.6 \\
& $\quad$ rhosis & & \\
& Non-alcoholic & $5,319,455$ & 8.5 \\
HCC & Cirrhosis & & \\
Other & & $9,737,184$ & 15.5 \\
All & & $18,427,319$ & 29.3 \\
\hline
\end{tabular}

a Includes: hepatoptosis; alcoholic liver damage unspecified; autoimmune hepatitis; toxic hepatitis; hepatitis unspecified
Table 7 Costs per hospital admission related to liver transplant in 2008

\begin{tabular}{llcl}
\hline $\begin{array}{l}\text { Disease } \\
\text { category }\end{array}$ & $\begin{array}{l}\text { Disease } \\
\text { subcategory }\end{array}$ & $\begin{array}{l}\text { Costs }(\boldsymbol{\epsilon}) \\
\text { relating to liver } \\
\text { transplant }\end{array}$ & $\begin{array}{l}\text { \% of liver } \\
\text { transplant } \\
\text { costs }\end{array}$ \\
\hline Viral hepatitis & All & 618,619 & 4.1 \\
& HBV & 206,206 & 1.4 \\
Cirrhosis & HCV & 309,310 & 2.0 \\
& All & $7,732,741$ & 50.7 \\
& Alcoholic & $5,876,883$ & 38.5 \\
& Cirrhosis & & \\
HCC & Non-alcoholic & $1,855,858$ & 12.2 \\
Other & Cirrhosis & & \\
All & & $4,330,335$ & 28.5 \\
\hline
\end{tabular}

a Includes: hepatoptosis; alcoholic liver damage unspecified; autoimmune hepatitis; toxic hepatitis; hepatitis unspecified

\section{Table 8 Causes of death in Portugal during 2011}

\begin{tabular}{ll}
\hline Disease category & $\begin{array}{l}\text { Crude rate/100,000 } \\
\text { of the population }\end{array}$ \\
\hline Cerebrovascular disease & 125.5 \\
Ischemic heart disease & 66.0 \\
Pneumonia & 51.4 \\
Diabetes mellitus & 43.1 \\
Malignant neoplasm of prostate & 36.1 \\
Malignant neoplasm colon and rectum & 35.9 \\
Malignant neoplasm of trachea, bronchus & 35.2 \\
$\quad$ and lung & 29.8 \\
Malignant neoplasm of female breast & 23.0 \\
Malignant neoplasm of stomach & 21.8 \\
Chronic hepatic disease and cirrhosis/HCC & \\
\hline
\end{tabular}


Table 9 Causes of premature death (less than 70 years of age) in Portugal during 2011 based on PYLL

\begin{tabular}{ll}
\hline Disease categories & Lost life years \\
\hline Motor vehicle traffic accidents & 19,974 \\
Malignant neoplasm of trachea, bronchus and lung & 19,880 \\
Chronic hepatic disease and cirrhosis/HCC & 17,586 \\
Cerebrovascular disease & 14,125 \\
Ischemic heart disease & 14,113 \\
Malignant neoplasm of colon/rectal & 11,540 \\
Malignant neoplasm of stomach & 10,158 \\
\hline
\end{tabular}

in 2008. Alcoholic cirrhosis was the leading cause of liver-related hospital admission and the main cost-driver, accounting for $€ 26,818,930$. Reducing alcoholic cirrhosis through education and legislation could decrease direct costs related to hospitalization and liver transplantation. The probable reduction in other alcohol-related public health problems, as traffic accidents, suggests that our analysis underestimates the potential economic, clinical and societal impact of tackling alcohol abuse [9, 21, 22]. There is evidence supporting the effectiveness and costeffectiveness of policies to reduce the impact of alcohol consumption. A thorough 2009 review concluded that initiating policies that regulate the environment in which alcohol is marketed are most effective [23]. In particular, measures to make alcohol more expensive, limiting its availability and regulating advertising practices were most cost effective [23]. A more recent report suggested that different interventions are more suitable depending on the prevalence of hazardous alcohol use, with taxation and population-wide interventions most cost-effective in settings of high prevalence and targeted interventions cost-effective for settings of low prevalence [24]. A report as part of the 2005-2007 ELSA (enforcement of national laws and self-regulation on advertising and marketing of alcohol) project found that Portugal had relatively few regulations regarding alcohol marketing compared with other European countries and in fact had no procedures to monitor these regulations [25]. It should be noted that new laws came into force in 2013 in Portugal that increased the legal age for the purchasing of spirits to 18.

Chronic hepatitis B virus (HBV) and HCV are, according to the International Agency for Research on Cancer [26], carcinogens in humans. Between 2 and $5 \%$ of patients with liver cirrhosis due to HCV develop HCC annually [27] and HBV causes approximately $20 \%$ of HCC cases in the western world [28]. In Portugal, the number of discharges due to viral hepatitis almost halved between 2000 and 2008, whereas the number of HCC cases doubled during the same time.
Universal HBV vaccination, introduced in Portugal in 2000, and improved detection as well as effective and well-tolerated treatments for viral hepatitis generally, and $\mathrm{HBV}$ and $\mathrm{HCV}$ in particular, probably contributed to this reduction $[29,30]$.

$\mathrm{HBV}$ and $\mathrm{HCV}$ that are refractory to treatment can progress to decompensated cirrhosis and HCC, resulting in high economic costs for public health services [31]. Worldwide, liver cancer is the sixth most common malignancy $(749,000$ new cases a year), the third most common cause of cancer-related mortality $(692,000$ deaths a year) and accounts for $7 \%$ of all cancers [32]. In Western countries, $90 \%$ of people who develop HCC have cirrhosis. Viral infection, alcohol, metabolic syndrome and immune-mediated conditions (such as primary biliary cirrhosis and autoimmune hepatitis) are major risk factors [33]. In Portugal, HCC imposes a considerable economic burden [7]. The socioeconomic burden is even higher when liver transplants and premature deaths are included. However, new anti-viral therapies reduce longterm liver complications and, therefore, result in fewer hospitalizations and less morbidity [34-38]. Future studies should assess the impact of these and other new treatments on the morbidity, mortality and socioeconomic burden imposed by viral liver diseases.

Although studies from several countries suggest that liver disease imposes a considerable socioeconomic burden $[1-4,11]$, no studies quantify costs imposed by liver disease in Portugal. This study aimed to provide basic data to inform the prioritization of health services. Our results show that interventions to prevent morbidity, mortality and premature death are urgently required. Tackling risk factors-such as intravenous drug use and alcohol consumption, unhealthy nutrition and a sedentary lifestyle-should be the main goal to reduce the societal, clinical and social toll imposed by liver diseases and other chronic non-communicable diseases in Portugal. Our results confirm, for example, that reducing alcohol consumption should be a main target of public health programmes in Portugal [21,39]. Against this background, managing end-stage liver disease through outpatient clinics that focus on compliance and education improve patient outcomes [40]. These strategies could minimize the direct and indirect costs associated with liver disease, particularly premature morbidity and mortality.

Our study is subject to certain limitations. Firstly, the study does not capture all direct costs from the perspective of the Portuguese National Health Service. For example, the analysis excludes direct costs imposed by ambulatory outpatients, including medication, medical consultations, treatments which do not need 
hospitalization and other direct costs incurred by visiting medical institutions. Secondly, the study did not estimate the indirect costs arising from, for example, lost workdays and the costs paid by caregivers to support the population with liver disease. However, these limitations mean that the study is likely to underestimate the costs imposed by liver disease to the Portuguese National Health Service and the wider economy. In addition, the PYLL index has its limitations, for example, it underestimates the importance of diseases that contribute to, but are not recorded as, the underlying cause of death, and there is a persistent controversy regarding the definition of an upper end point during its calculation.

\section{Conclusions}

In 2011, liver disease was the 10th most common cause of death and the third most important cause of premature death in Portugal. Alcohol cirrhosis was the leading cause of liver-related hospital admissions between 2001 and 2008. It appears that liver disease represents a considerable social and economic problem in Portugal. Our results suggest that educational, legislative and therapeutic interventions to prevent morbidity, mortality and premature death from liver disease are urgently required.

\section{Abbreviations}

ALOS: average length of stay; DGS: Direcção Geral de Saude; HBV: hepatitis B; HCV: hepatitis C virus; HCC: hepatocellular carcinoma; ICD: international classification of diseases; INE: Instituto Nacional de Estatística; PYLL: potential years of life lost.

\section{Authors' contributions}

SV, RTM, JG and JV were involved in the conception and design of the study, analysis of the data and development of the first draft. All authors provided feedback on the various draft versions of the manuscript. All authors read and approved the final manuscript.

\section{Author details}

${ }^{1}$ Department of Gastrenterology and Hepatology, Hospital de Santa Maria, Centro Hospitalar Lisboa Norte, Avenida Professor Egas Moniz, 1649-035 Lisbon, Portugal. ${ }^{2}$ Direcção Geral de Saúde, Alameda D. Afonso Henriques,45, 1049-005 Lisbon, Portugal.

\section{Acknowledgements}

The authors would like to acknowledge the editorial assistance of Mark Greener and Jamie Hopps, ROCK Unlimited, paid for by Gilead. However, Gilead had no input into the design, conduct or reporting of the study.

\section{Competing interests}

The authors declare that they have no competing interests.

Received: 5 June 2015 Accepted: 20 January 2016

Published online: 03 February 2016

\section{References}

1. Ray KW, Brown RS, Terrault NA, Hashem ES. Burden of liver disease in the United States: summary of a Workshop. Hepatology. 2002;36:227-42.

2. Lee S, Woojin C, Kyung-Rae H. Socioeconomic costs of liver disease in Korea. Korean J Hepatol. 2011;17:274-91.
3. lacobucci G. Liver disease rises in England while falling elsewhere in Europe, report says. BMJ. 2012;345:e7931.

4. Eurostat European social statistics 2013 edition. (http://epp.eurostat. ec.europa.eu/cache/ITY_OFFPUB/KS-FP-13-001/EN/KS-FP-13-001-EN. PDF).

5. Adam R, Karam V, Delvart $\mathrm{V}$, et al. Evolution of indications and results of liver transplantation in Europe. A report from the European liver transplant registry (ELTR). J Hepatol. 2012;57:675-88.

6. Blachier M, Leleu H, Peck-Radosavljevic M et al. The burden of liver disease in Europe. European association for the study of the liver (EASL). (http://www.easl.eu/assets/application/files/54ae845caec619f_file.pdf).

7. Marinho RT, Giria J, Moura MC. Rising costs and hospital admissions for hepatocellular carcinoma in Portugal (1993-2005). World J. Gastroentero. 2007;13:1522-7.

8. Cortez-Pinto H, Gouveia M, dos Santos Pinheiro L, et al. The burden of disease and the cost of illness attributable to alcohol drinking-results of a national study. Alcohol Clin Exp Res. 2010;34:1442-9.

9. Cortez-Pinto H, Marques-Vidal P, Monteiro E. Liver disease-related admissions in Portugal: clinical and demographic pattern. Eur J Hepatol. 2004:16:873-7.

10. European Association for the Study of the Liver Press Office. Chronic hepatic diseases generate high costs to Europe. Separate Study links acute-on-chronic liver failure to high short-term mortality. (http://www. easl.eu/assets/application/files/f3263cb5942c12f_file.pdf).

11. Nader LA, de Mattos AA, Bastos GA. Burden of liver disease in Brazil. Liver Int. 2014;. doi:10.1111/liv.12470.

12. John RM, Sung HY, Max W. Economic cost of tobacco use in India, 2004. Tob Control. 2009;18:138-43.

13. Fenoglio P, Parel V, Kopp P. The social cost of alcohol, tobacco and illicit drugs in France, 1997. Eur Addict Res. 2003;9:18-28.

14. Colagiuri S, Lee CM, Colagiuri R, et al. The cost of overweight and obesity in Australia. Med J Aust. 2010;192:260-4.

15. Zhang W, Bansback N, Anis AH. Measuring and valuing productivity loss due to poor health: a critical review. Soc Sci Med. 2011;72:185-92.

16. OECD Health Statistics 2014. Definitions, sources and methods. (http:// www.oecd.org/health/healthdata(2014)).

17. CDC. Premature mortality in the United States: public health issues in the use of the years of potential life lost. (http://www.cdc.gov/mmwr/ preview/mmwrhtml/00001773.htm).

18. Pordata. Taxa de actividade: total e por sexo (\%). (http://www.pordata. $\mathrm{pt} /$ Portugal/Taxa+de+actividade+total+e+por+sexo+(percenta gem)-547).

19. Pordata. Taxa de actividade: total e por grupo etário (\%). (http://www. pordata.pt/Portugal/Taxa+de+actividade+total+e+por+grupo+etario + (percentagem)-1321).

20. Plano Nacional de Saúde 2012-2016. (http://pns.dgs.pt/nhp-in-english/).

21. George F. Causes of deaths in Portugal and challenges in prevention. Acta Med Port. 2012;25:61-3.

22. Rehm J, Dawson D, Frick U, et al. Burden of disease associated with alcohol use disorders in the United States. Alcohol Clin Exp Res. 2012;38:1068-77.

23. Anderson P, Chisholm D, Fuhr DC. Effectiveness and cost-effectiveness of policies and programmes to reduce the harm caused by alcohol. Lancet. 2009;373(9682):2234-46.

24. Chisholm D, Rehm J, Van Ommeren M, Monteiro M. Reducing the global burden of hazardous alcohol use: a comparative cost-effectiveness analysis. J Stud Alcohol. 2004;65(6):782-93.

25. Anderson P. The impact of alcohol advertising: ELSA project report on the evidence to strengthen regulation to protect young people. Utrecht: National foundation for alcohol prevention; 2007.

26. International Agency for Research on Cancer. IARC Monographs on the evaluation of carcinogenic risks to humans (volume 59): Hepatitis viruses. Lyon: IARC; 1994.

27. Bruix J, Barrera JM, Calvet $X$, et al. Prevalence of antibodies to hepatitis $C$ virus in Spanish patients with hepatocellular carcinoma and hepatic cirrhosis. Lancet. 1989;2:1004-6.

28. Manns MP, McHutchison JG, Gordon SC, et al. Peginterferon alfa-2b plus ribavirin compared with interferon alfa-2b plus ribavirin for initial treatment of chronic hepatitis C: a randomised trial. Lancet. 2001;358:958-65.

29. Liaw YF, Sung JJ, Chow WC, et al. Lamivudine for patients with chronic hepatitis B and advanced liver disease. N Engl J Med. 2004;351:1521-31. 
30. Sarrazin C, Berg T, Ross RS, et al. Prophylaxis, diagnosis and therapy of hepatitis $C$ virus ( $\mathrm{HCV}$ ) infection: the German guidelines on the management of HCV infection. Z Gastroenterol. 2010;48:289-351.

31. van der Meer AJ, Veldt BJ, Feld JJ, et al. Association between sustained virological response and all-cause mortality among patients with chronic hepatitis C and advanced hepatic fibrosis. JAMA. 2012;308:2584-93.

32. International Agency for Research on Cancer. Cancer. Mondial. (http:// www-dep.iarc.fr)

33. Shariff MI, Cox IJ, Gomaa Al, et al. Hepatocellular carcinoma: current trends in worldwide epidemiology, risk factors, diagnosis and therapeutics. Expert Rev Gastroenterol Hepatol. 2012;3:353-67.

34. Chhatwal J, Ferrante SA, Brass C, et al. Cost-effectiveness of boceprevir in patients previously treated for chronic hepatitis $C$ genotype 1 infection in the United States. Value Health. 2013;16:973-86.
35. Cure S, Bianic F, Gavart S, et al. Cost-effectiveness of telaprevir in combination with pegylated interferon alpha and ribavirin in previously untreated chronic hepatitis C genotype 1 patients. J Med Econ. 2014;17:65-76.

36. Blázquez-Pérez A, SanMiguel R, Mar J. Cost-effectiveness analysis of triple therapy with protease inhibitors in treatment-naive hepatitis $C$ patients. Pharmacoeconomics. 2013;31:919-31.

37. Chen LP, Zhao J, Du Y, et al. Antiviral treatment to prevent chronic hepatitis B or C-related hepatocellular carcinoma. World J Virol. 2012;1:174-83.

38. Feeney ER, Chung RT. Antiviral treatment of hepatitis C. BMJ. 2012;349:93308.

39. Fan JG, Cao HX. Role of diet and nutritional management in non-alcoholic fatty liver disease. J Gastroenterol Hepatol. 2012;28:81-7.

40. McAfee JL. Developing an advanced practice nurse-led liver clinic. Gastroenterol Nurs. 2012;35:215-24.

\section{Submit your next manuscript to BioMed Central and we will help you at every step:}

- We accept pre-submission inquiries

- Our selector tool helps you to find the most relevant journal

- We provide round the clock customer support

- Convenient online submission

- Thorough peer review

- Inclusion in PubMed and all major indexing services

- Maximum visibility for your research

Submit your manuscript at www.biomedcentral.com/submit
() Biomed Central 